\title{
Effect of hydrogen on the damping properties of NiTi alloys
}

\author{
B. Coluzzi, A. Biscarini, R. Campanella, G. Mazzolai and F.M. Mazzolai \\ Department of Physics, Istituto Nazionale di Fisica per la Materia Condensata, \\ University of Perugia, Italy
}

\begin{abstract}
The effect of hydrogen dopings on the internal friction and the Young's modulus has been investigated in the alloys $\mathrm{Ni}_{50.8} \mathrm{Ti}_{49.2}, \mathrm{Ni}_{49} \mathrm{Ti}_{51}$ and $\mathrm{Ni}_{40} \mathrm{Ti}_{50} \mathrm{Cu}_{10}$ as a function of the hydrogen content $\mathrm{n}_{\mathrm{H}}\left(\mathrm{n}_{\mathrm{H}}=\mathrm{H} / \mathrm{Me}\right.$ atomic) and frequency. It has been found that hydrogen strongly affects the anelastic spectrum of these alloys in the temperature domain. The IF peak occurring at the austenite-martensite $(\mathrm{A}-\mathrm{M})$ transition in the solubilized $\mathrm{Ni}_{50.8} \mathrm{Ti}_{49.2}$ alloy is enhanced by hydrogen at low contents $\left(n_{H}<1.3\right)$ and reduced at high hydrogen contents $\left(n_{H}>1.3\right)$. An additional IF peak is introduced in the same alloy by $\mathrm{H}$ for $\mathrm{n}_{\mathrm{H}}>1.3$. This second peak, which appears at temperatures higher than the martensite start temperature $M_{s}$, is likely due to hydrogen re-distributions over subsets of interstitial sites within a hydride, under the applied alternating stress fields associated with the sample vibrations. The relaxation parameters of this peak, which is thermally activated, are in keeping with the expectations from $\mathrm{H}$ diffusion high temperature data.

In the aged alloy $\mathrm{Ni}_{49} \mathrm{Ti}_{51} \mathrm{H}$ suppresses the low temperature IF background and introduces a thermally activated relaxation, which is associated with $\mathrm{H}$ dragging processes by twin boundaries. A relaxation effect, again ascribable to $\mathrm{H}$ dragging processes by twin boundaries, has also been evidenced with the $\mathrm{Ni}_{40} \mathrm{Ti}_{50} \mathrm{Cu}_{10}$ alloy.

The most remarkable result of these investigations is the fact that hydrogen appears to be a very sensitive tool to probe twin boundary dynamics.
\end{abstract}

